\title{
DESIGN OF A TWO-DIMENSIONAL BALLISTOCARDIOGRAPH ${ }^{2}$
}

\author{
By JOHN R. BRAUNSTEIN, CECIL E. OELKER, AND ROBERT C. GOWDY ${ }^{2}$ \\ (From the Cardiac Laboratory, Department of Internal Medicine, University of Cincinnati Col- \\ lege of Medicine, Cincinnati General Hospital; and the Department of Physics, Gradu- \\ ate School of Arts and Sciences, University of Cincinnati, Cincinnati, Ohio)
}

(Submitted for publication May 10, 1950; accepted, June 13, 1950)

The ballistocardiograph, in its usual form, is an instrument with one degree of freedom which measures the movement of the body resulting from the heart beat (1). The displacement permitted is from head to foot; and may be recorded with the subject supine (1-3), standing (4-6), or even tilted (7). J. W. Gordon (8), who built the first model, a light bed swung by four ropes from a trestle, probably obtained his inspiration while standing on a spring weighing machine; for his first recording is taken from one of these. Yandell Henderson (9), who was unaware of Gordon's earler work, in accounting for his own motivation, took a somewhat different approach. "Probably everyone," he says, "has occasionally been kept awake by the rattling or creaking of his bed in unison with his heart beat." Henderson's first records were obtained from a plank suspended by wires from a high ceiling. "With such a table," he notes, "the heart beat causes not only longitudinal, but also lateral movements. The latter have not yet been examined in detail. In fact, it is necessary, in order to record the longitudinal movements with accuracy, that the lateral movements should be prevented." So far as can be determined some forty years later, these lateral movements, which it is, in part, the purpose of this study to record, have been prevented in subsequent models, although instruments of varying sizes, shapes and characteristics have been built.

A single ballistic tracing with three degrees of freedom (head to foot, side to side, front to back) has been published recently by Hamilton (10). $\mathrm{He}$ does not, however, state how the record was obtained. "Nevertheless," this same severe critic of the instrument says elsewhere, "the forms which the apparatus take are as diverse as the

1 This project was supported in part by a grant from the National Heart Institute of the U. S. Public Health Service.

2 Died March 27, 1950. minds of the men who construct them." (11) These have been ably reviewed by Starr (2), who at the same time, introduced a constrained instrument with a loaded frequency of the order of 10 c.p.s. Several years later, using a different approach, Nickerson (1) developed a highly damped instrument with a loaded frequency of 1.5 c.p.s. Each of these has gained a variety of acceptance; but, since the characteristics of the two systems are so diverse, we found it necessary before designing an instrument for our study, to reexamine the entire question of ballistic theory.

Needless to say, there is no apparent reason why the characteristics should in any way differ with respect to the head to foot or side to side component. Each merely represents the sum of the components of the vector forces in the frontal plane. Hence the theory which follows may be considered as applying equally to each.

\section{EQUATIONS OF MOTION}

We may consider the ballistocardiograph as a ballistic system consisting of a mass $M$, a constraining spring constant $K$, and a damping force which is proportional to the velocity and always opposite to the direction of motion. Upon this ballistic system is impressed a driving force which is a function of time, $F(t)$.

Now by Fourier's expansion we may write:

$$
F(t)=\sum_{n=0}^{\infty} A_{n} \sin \left(n \omega t+\delta_{n}\right),
$$

where $\omega=2 \pi \times$ frequency, $n$ is the order of the harmonic, $A_{n}$ is the amplitude of the $n$th harmonic given by

$$
A_{n}^{2}=a_{n}^{2}+b_{n}^{2}
$$

and $\delta_{n}$ the phase angle of the $n$th harmonic as determined from

$$
\tan \delta_{\mathbf{n}}=\frac{b_{n}}{a_{n}},
$$

where $a_{n}$ and $b_{n}$ are the usual Fourier coefficients of the nth sine and cosine terms, respectively.

By Newton's second law we may also write

$$
F(t)=M x^{\prime \prime}+C x^{\prime}+K x=\sum_{n=0}^{\infty} A_{n} \sin \left(n \omega t+\delta_{n}\right),
$$


where $x$ is the displacement, $x^{\prime}$ is the velocity, $x^{\prime \prime}$ is the acceleration, $M$ is the mass of the moving matter, $C$ is the coefficient of viscous damping, and $K$ is the elastic coefficient of the spring.

Considering a single member of the Fourier series, the differential equation becomes:

$$
\mathrm{Mx}^{\prime \prime}+\mathrm{Cx}^{\prime}+\mathrm{Kx}=\mathrm{A} \sin (\omega \mathrm{t}+\delta) .
$$

The steady-state solution of this equation is (12)

or

$$
x=\frac{A}{\sqrt{(C \omega)^{2}+\left(K-M \omega^{2}\right)^{2}}} \sin (\omega t+\delta-\phi)
$$

$$
x=\frac{\frac{A}{K}}{\sqrt{\left(1-\frac{\omega^{2}}{\omega_{n}^{2}}\right)^{2}+\left(2 \frac{C}{C_{0}}-\frac{\omega}{\omega_{n}}\right)^{2}}} \sin (\omega t+\delta-\phi),
$$

where

$$
\phi=\tan ^{-1} \frac{C \omega}{K-M \omega^{2}}=\tan ^{-1} \frac{2 \frac{C}{C_{0}} \frac{\omega}{\omega_{n}}}{1-\left(\frac{\omega}{\omega_{n}}\right)^{2}},
$$

$C_{0}$ is the so called critical damping defined by

$$
C_{0}=2 M \sqrt{\frac{K}{M}}=2 \sqrt{M K}
$$

and $\omega_{n}$ is the resonance angular frequency of the system given by

$$
\omega_{n}=\sqrt{\frac{\bar{K}}{M}}=2 \pi f_{n}
$$

The term $\frac{A}{K}$ can be interpreted as the deflection of the spring under a load, A. We call this, to choose a term, the desired deflection, $\mathbf{x}_{\mathbf{d}}$.

The ratio of the amplitude of the damped case to the desired amplitude is given by:

$$
\frac{x}{x_{d}}=\frac{1}{\sqrt{\left(1-\frac{\omega^{2}}{\omega_{n}^{2}}\right)^{2}+\left(2 \frac{C}{C_{0}} \frac{\omega}{\omega_{n}}\right)^{2}}} .
$$

For critical damping, i.e.,

$$
\begin{gathered}
\frac{C}{C_{c}}=1 \\
\frac{x}{x_{d}}=\frac{\omega_{n}^{2}}{\omega_{n}^{2}+\omega^{2}}=\frac{\left(2 \pi f_{n}\right)^{2}}{\left(2 \pi f_{n}\right)^{2}+(2 \pi f)^{2}}=\frac{f_{n}^{2}}{f_{n}^{2}+f^{2}} .
\end{gathered}
$$

Figures 1 and 2 show curves plotted from the equation above. Curves for $\phi$, the phase angle between the force and displacement are shown for various degrees of damping in Figure 3.

\section{CHOICE OF LOW OR HIGH FREQUENCY TABLE}

There has been"much discussion concerning requirements for a desirable ballistocardiograph. Nickerson and Curtis (1) have chosen as their criterion the ratio of the amplitude of table motion from equation (2) to the motion of the so called "ideal" case. In this ideal case the system is taken as being without constraint and damping, that is in equation (1), C and $\mathrm{K}$ are both zero. This gives for the ideal deflection

$$
x=\frac{A}{M \omega^{2}} \sin (\omega t+\delta) .
$$

It is apparent that the amplitude of this motion is not constant for a constant amplitude input but depends upon the frequency of the impressed force. For a forcing function containing several frequencies, the amplitude of the various response components will depend upon their frequency, and thus the body motion will not reproduce the forcing function.

It was felt that a better criterion for the choice of table is that the motion of the table should reproduce accurately the forcing function impressed on the table. This means that two requirements must be met: $A$ ) the amplitude of response of the table should not depend on the frequency but should be proportional to the amplitudes of the applied forces; and $B$ ) the $\phi$ 's should be proportional to the impressed frequency.

For $f / f_{n}$ small, $f_{n}$ must be much larger than $f$ and $f_{n}{ }^{2}$ will be very much larger than $f^{2}$. Then from equation (4):

$$
\frac{x}{x_{d}}=\frac{f_{n}^{2}}{f_{n}^{2}+f^{2}} \cong \frac{f_{n}^{2}}{f_{n}^{2}}=1 \text {. }
$$

Thus requirement $A$ ) is fulfilled when $\mathrm{f} / \mathrm{f}_{\mathrm{n}}$ is small.

Also from equation (3) for a critically damped table,

$$
\begin{aligned}
& C=C_{0} \\
& \phi=\tan ^{-1} \frac{C_{0} \omega}{K-M \omega^{2}}=\tan ^{-1} \frac{2 \omega_{n} \omega}{\omega_{n}^{2}-\omega^{2}} \\
&=\tan ^{-1} \frac{2 \frac{\omega}{\omega_{n}}}{1-\frac{\omega^{2}}{\omega_{n}^{2}}}=\tan ^{-1} \frac{2 \frac{f}{f_{n}}}{1-\frac{f^{2}}{f_{n}^{2}}} \\
& \simeq \tan ^{-1} 2 \frac{f}{f_{n}} \cong 2 \frac{f}{f_{n}}
\end{aligned}
$$

and requirement $B$ ) is met.

This may also be seen from the curves of Figure 1. Picking a small value of $f / f_{n}$ (where $f$ is the highest frequency of the forcing function) gives a ratio of $x / x_{d} 1$ for all frequencies. Also from Figure 3 we see that for $f / f_{n}$ small the phase shift, $\phi$, will be very nearly proportional to $f$ for all impressed frequencies. Hence a high natural frequency table will give an accurate reproduction of the forcing function.

Consider now a large ratio of $f / f_{n}$. Now $f>f_{n}$ and $f^{2} \gg f_{n}^{2}$ and equation (4) becomes,

$$
\frac{x}{x_{d}}=\frac{f_{n}^{2}}{f_{n}^{2}+f^{2}} \cong \frac{f_{n}^{2}}{f^{2}}=\left(\frac{f_{n}}{f}\right)^{2} \text {, }
$$

which varies rapidly with $f$.

Also from the equation for $\phi$ for critical damping,

$\phi=\tan ^{-1} \frac{C_{0} \omega}{K-M \omega^{2}}=\tan ^{-1} \frac{2 \frac{f}{f_{n}}}{1-\left(\frac{f}{f_{n}}\right)^{2}} \cong \tan ^{-1}\left(-2 \frac{f}{f_{n}}\right)$

$\simeq \tan ^{-1}(0) \cong 180^{\circ}$

which is not proportional to $f$ as desired. Thus a low frequency table will not accurately reproduce the impressed force. 


\section{DAMPING}

We see next from Figure 1 that the effect of resonance is practically gone for $\mathrm{C} / \mathrm{C}_{\mathrm{c}}$ between 0.5 and 1.0. Also $x / x_{d}$ is practically constant for $f / f_{n}$ $<0.4$. Therefore, if we make $f_{n}>2.5 f$ for the highest harmonic and $\mathrm{C} / \mathrm{C}_{\mathrm{c}}>0.5$, good reproduction will be obtained.

An investigation by Starr using fresh cadavers indicated that the damping supplied by the tissue elasticity of the body was essentially constant for various body builds. The damping supplied by the body was found to be approximately 0.5 of critical damping for a high frequency table. Hence Starr concluded correctly that for his table additional damping is not necessary. Some added damping, however, may be desirable to assure adequate damping for all patients. It is also evident that determining critical damping by use of an equivalent mass of cast iron will result in overdamping when the patient is placed on the table.

\section{HARMONIC ANALYSIS}

Since the design of the table depends upon the highest frequency component present in the forcing function, a Fourier analysis of the ballistocardiogram was undertaken. A selected ordinate method was considered sufficiently accurate for the study, and Collins Harmonic Analysis Grids which require a curve with a 10 inches baseline were used.

Three different curves from a normal subject were chosen and photographically enlarged to a 10 inches base. The selected ordinates chosen by the analysis grids were added by use of a Dietzgen map measure.

The three curves chosen were of equal time length so that the frequencies of the various harmonics would correspond.

The analysis of the three curves gives the results for the first ten harmonics shown in Table I. The values of curve No. 3 were multiplied by two to give the same relative amplitudes to the harmonics since the complexes of curve No. 3 were small initially.

From the table it is seen that the harmonics above the sixth are comparatively small and for most practical purposes may be ignored.

There are also seen to be several instances where a particular harmonic is considerably larger or

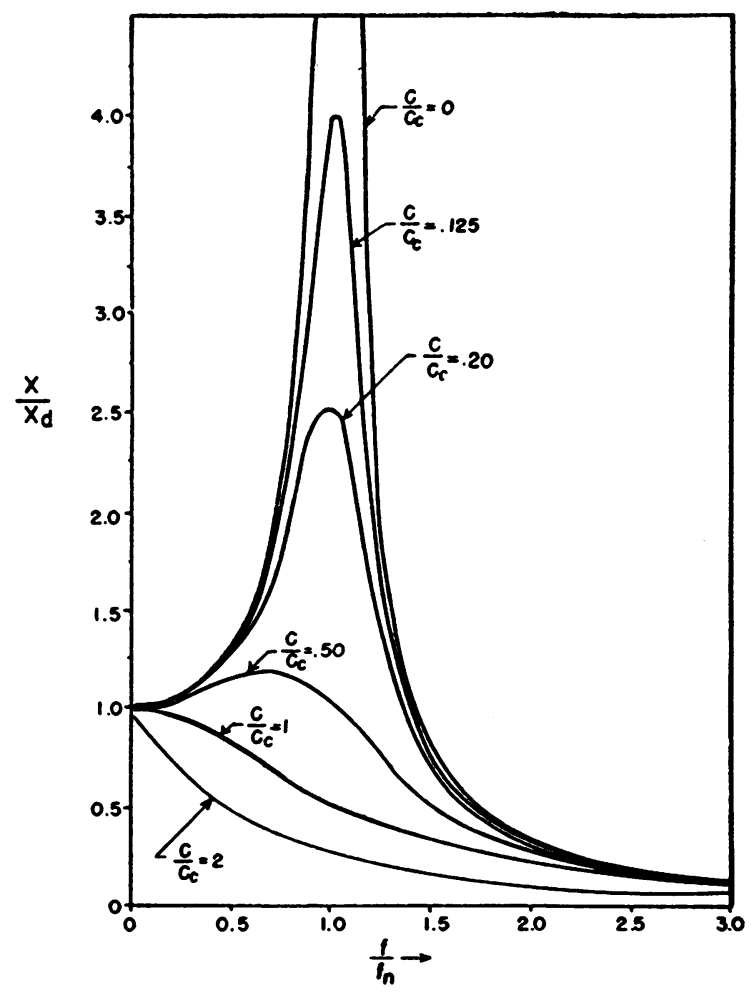

Fig. 1. Ratio of the Resultant Deflection, $x$, to the Desired Deflection, $x_{d}$, vs. The Ratio of the IMpressed Frequency, $f$, to the Natural Frequency $f_{n}$ for Various Values of Damping the Ratio

smaller than the other two. For example, the first harmonic of the first curve is only about one third of the values found for the other two curves.

The accuracy of the method was checked by a synthesis of curve No. 1 using the Fourier coefficients found by analysis of the curve. The results using the first five and the first ten harmonic components are shown in Figure 4. The Fourier

TABLE I

Amplitudes of the various harmonic components of three ballistic curves as determined by a Fourier analysis

\begin{tabular}{c|c|c|c|c}
\hline \hline $\begin{array}{c}\text { Harmonic } \\
\text { number }\end{array}$ & No. 1 & No. 2 & No. 3 & $2 \times$ No. 3 \\
\cline { 3 - 4 } 1 & 0.19 & 0.57 & 0.32 & 0.64 \\
2 & 0.68 & 0.86 & 0.56 & 1.12 \\
3 & 1.31 & 1.41 & 0.65 & 1.30 \\
4 & 0.94 & 1.03 & 0.49 & 0.96 \\
5 & 0.64 & 0.50 & 0.47 & 0.94 \\
6 & 0.49 & 0.40 & 0.28 & 0.56 \\
7 & 0.20 & 0.22 & 0.07 & 0.14 \\
8 & 0.14 & 0.11 & 0.05 & 0.10 \\
9 & 0.09 & 0.08 & 0.07 & 0.14 \\
10 & 0.04 & 0.08 & 0.04 & 0.08 \\
\hline
\end{tabular}




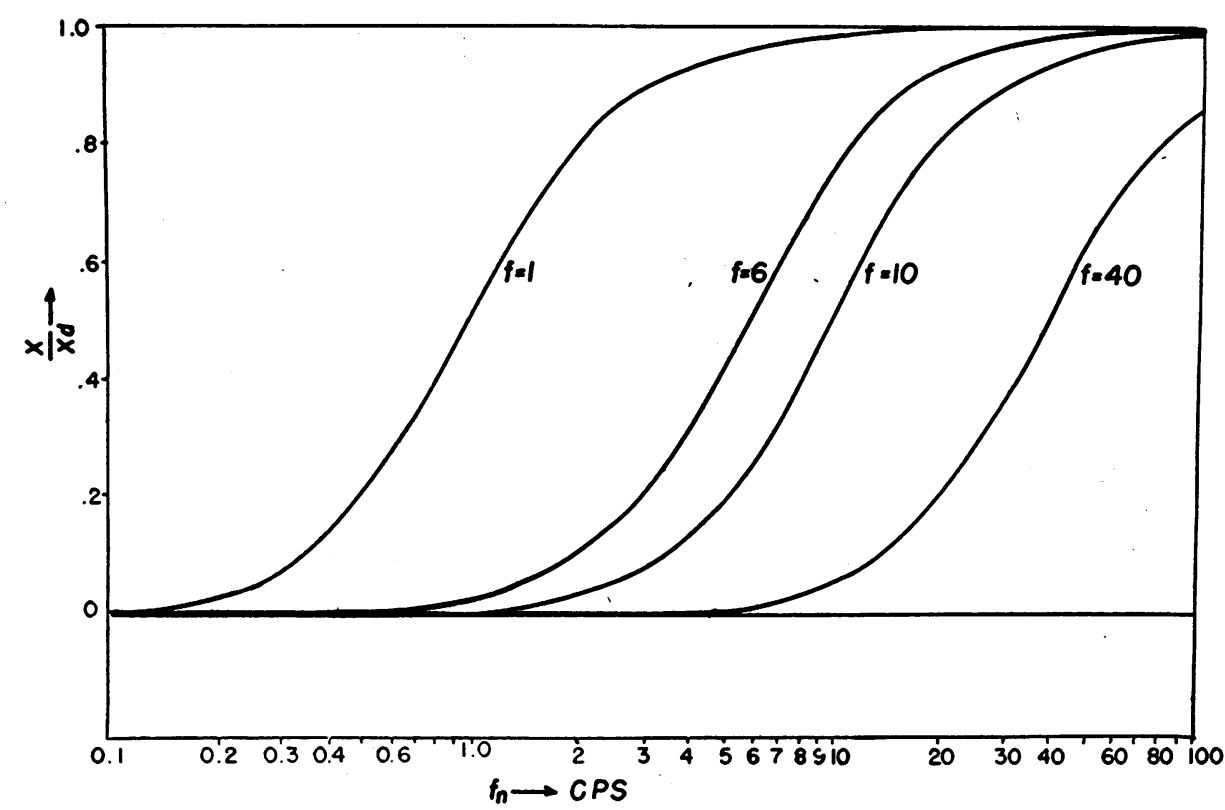

Fig. 2. Ratio of the Resultant Deflection to the Desired Deflection vs. the Natural

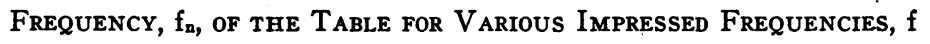

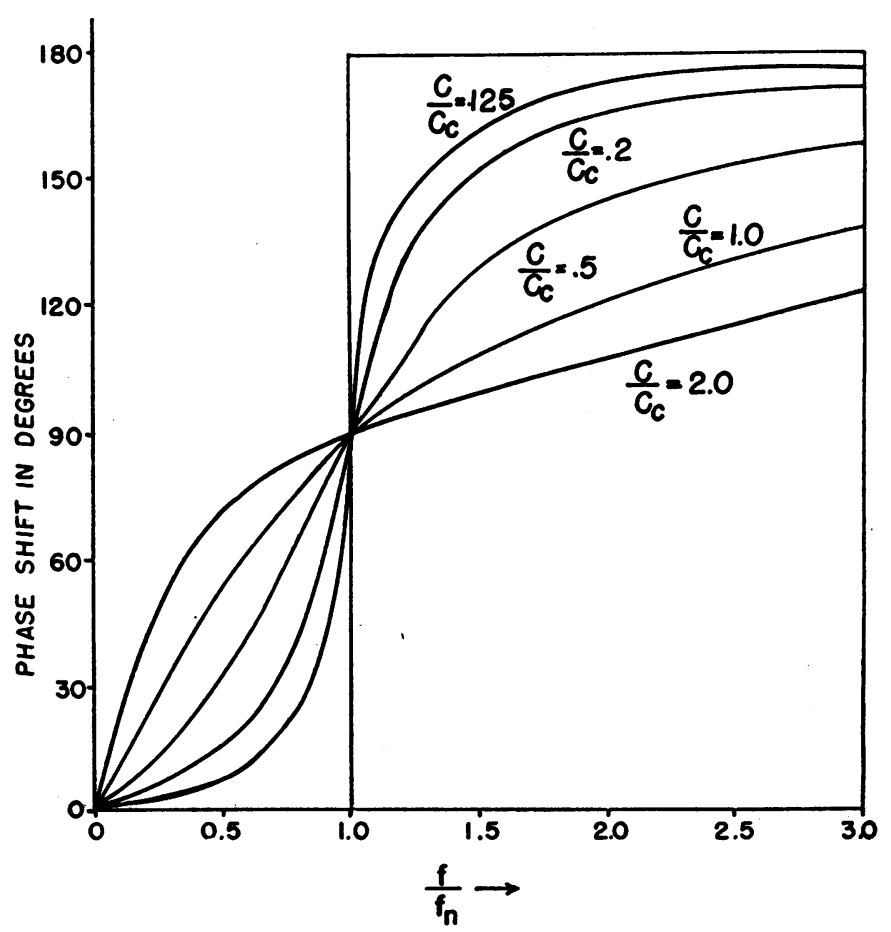

Fic. 3:

For various values of the damping ratio, the phase angle between the impressed force and the table motion is plotted against the ratio of the impressed frequency, $f$, to the natural frequency, $f_{u}$. 


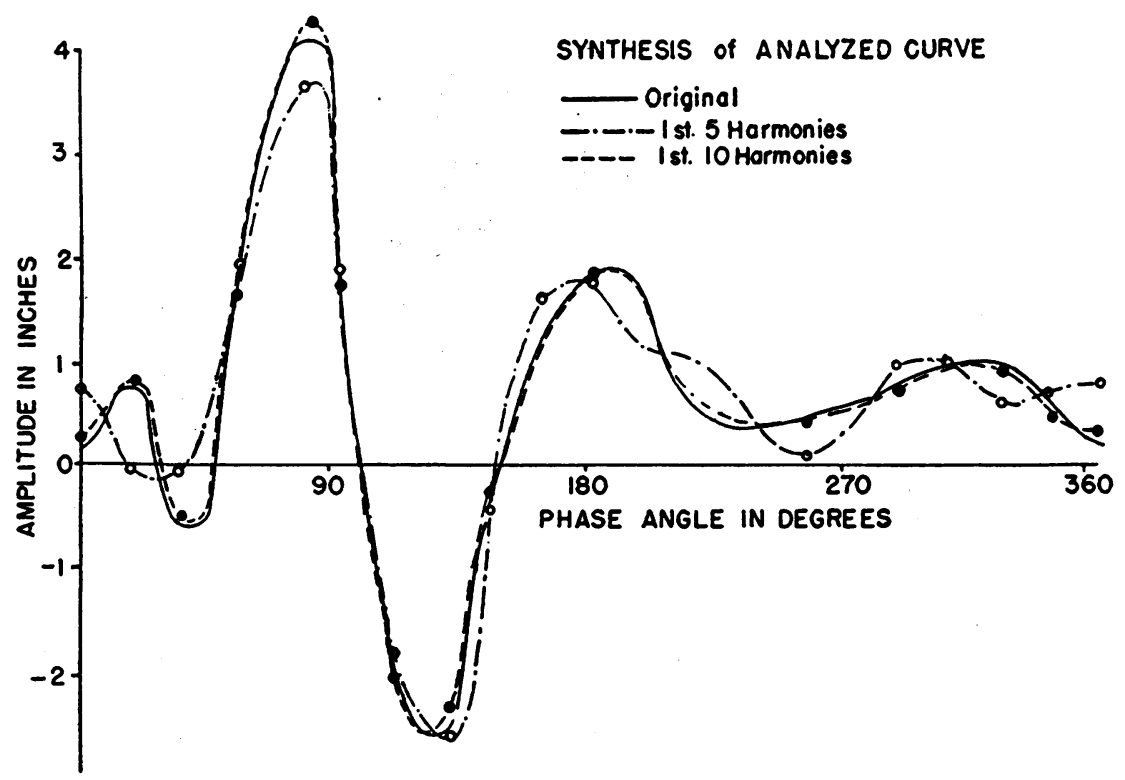

Fig. 4. Synthesis of One of the Analysed Curves

This compares the original curve, a curve composed of the first five harmonics and a curve made up of the first ten harmonics.

coefficients are believed to be accurate at least \pm .08 and are more probably of the order of \pm .04 . The chief error is in the determination of the center of an enlarged curve but since the error is apt to be taken positive in one reading and negative in another, over a series of 50 to 60 readings the error is self compensating.

This analysis shows that the components above the sixth are small and may be neglected for practical purposes. Thus the ballistocardiograph must be designed to give a good response to at least six cycles per second. This requires a high frequency table of at least 15 cycles per second. Truer recording will, of course, be obtained by use of a still higher natural frequency.

\section{MECHANICAL DESIGN}

It is apparent that the bed of the ballistocardiograph should be made as light as possible to give maximum amplitude of motion and sensitivity to the device. At the same time it should be as rigid as possible so it does not bow or deform the springs when the patient is lying on the table.

The base, on the other hand, should be as massive and rigid to furnish a solid support for the springs and the bed.

The table top of this instrument was designed to give less than $1 / 32$ inch deflection with a normal person sitting in the center of one edge of the top. An aluminum alloy, Duraluminum 24-St, was used to achieve high tensile strength with minimum weight. It may be seen in cross section in Figure 5. The base is made of two small, cast iron lathe beds and two large lathe pedestals. These are bolted together with $1 / 2$ inch Allen-head bolts. The top is supported on the base by four steel rods $51 / 2$ inches in length and $3 / 8$ inch in diameter. Damping is supplied by copper bars fastened to the table moving through a magnetic field produced by permanent magnets. One of these is mounted at each end of the table. The total weight of the base and magnets is approximately $2,000 \mathrm{lbs}$. The motion of the table is translated into an electrical signal by Statham strain gauges. One of these records the head to foot movement of the table, while the other three measure the side to side components and are mounted one at each end and one in the middle. The output of the strain gauge bridge circuit is fed into a Brush 310-S amplifier and recorded with a BL 902 pen motor. A bank of six of these pen motors is arranged for recording simultaneously on a single sheet of paper so that the output of the four strain gauges can be taken off together with the electrocardiograph and pneumograph. 


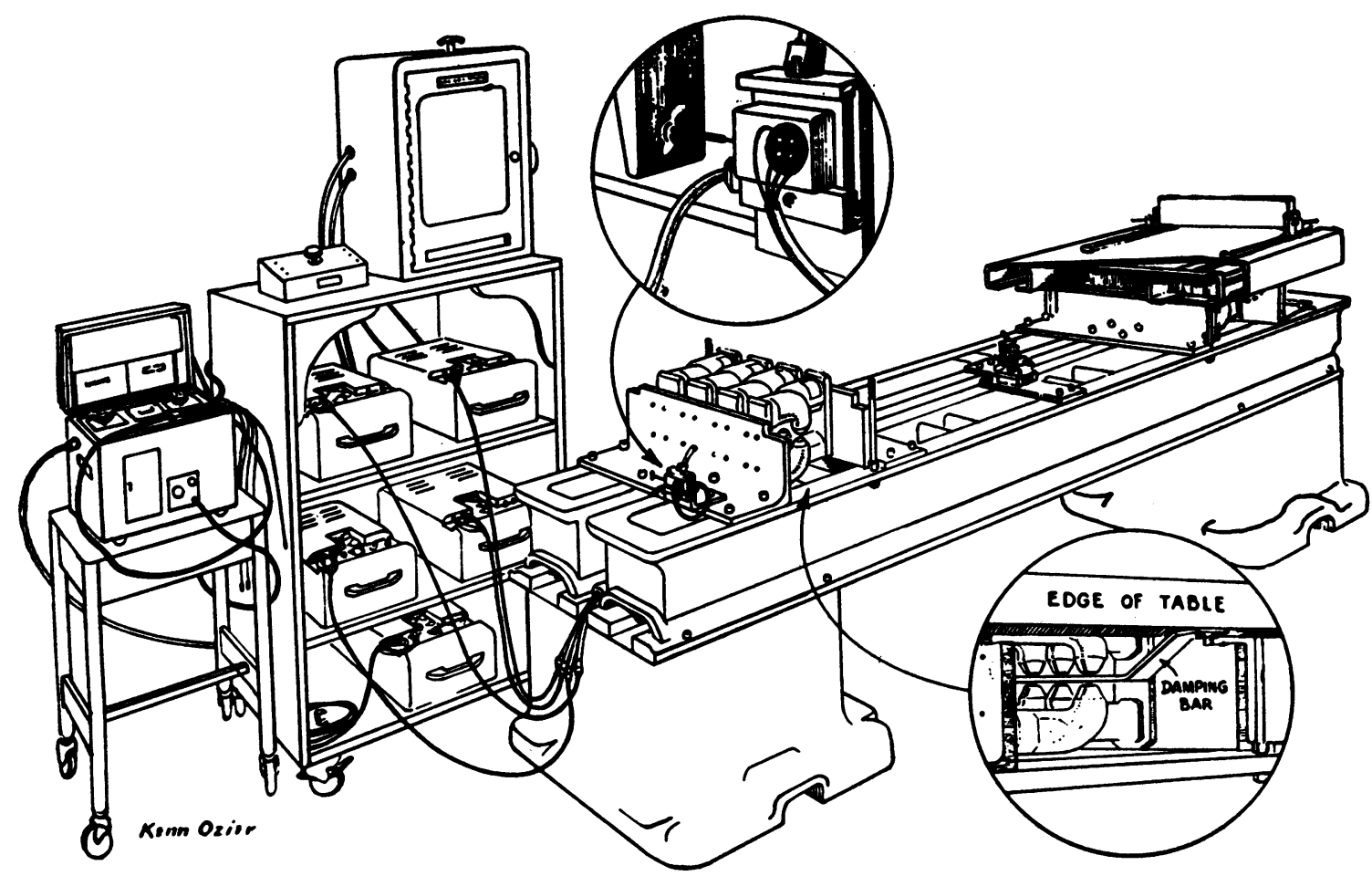

Fig. 5. Details of Construction of the Two-Dimensional Instrument

The completed instrument has the following characteristics :

1.) The table top weighs $49 \mathrm{lbs}$. An added foot rest increases the weight to 51 lbs., the copper damping bars each weighs 5 lbs., hence the total no-load weight of the table top is $61 \mathrm{lbs}$.

2.) From the load deflection curve a value of $4.82 \times 10^{3} \mathrm{lbs}$. per inch was found for the spring constant $\mathrm{K}$.

3.) The measured value of no load longitudinal frequency was found to be 27.8 c.p.s. which agrees exactly with that calculated using $61 \mathrm{lbs}$. mass and $\mathrm{K}=4.82 \times 10^{3} \mathrm{lbs}$./in.

The frequency of the table with 150 lbs. rigid load was measured and found to be 15 cycles per second.

The amount of damping was determined from a no-load free vibration curve with the damping bars fastened to the table. Calculation of the logarithmic decrement of the curves showed about $10 \%$ critical damping.

The maximum motion of the table as caused by the heart beat of a normal young person is of the order of 0.00015 inch. This is amplified and recorded as about $3 / 4$ inch on the paper. Thus an amplification of about 5,000 is achieved.

A record taken on a healthy young adult is illustrated in Figure 6. The usual head to foot component is recorded in the top channel. The next three channels record the side to side motion of the table at the head end, center and foot end in the order mentioned. The gauges are arbitrarily connected so that with a supine subject a movement to the left is recorded as an upward deflection, and a movement to the right as a downward deflection. The pneumograph is recorded on the fifth channel. Here an upward deflection represents inspiration. Lead I of the electrocardiograph is recorded in channel six. An inspection of the three side to side components shows that the movement of the table is greatest at the head end. It may also be seen that the movement of the foot end is $180^{\circ}$ out of phase with the other two, thus demonstrating a torque with a pivot somewhere below the waist. Whether the amplitude is greater at the center or at the foot end appears from a study of other records, to depend upon the body build of the subject. At the head 
TABLE II

Successive heights of $I$ and $J$ waves during two respiratory cycles before and after correction for the lateral component

\begin{tabular}{|c|c|c|c|c|c|c|c|c|c|c|}
\hline $\begin{array}{l}\text { Height of I wave } \\
\text { Corrected height } \\
\text { Per cent departure from } \\
\text { corrected figure }\end{array}$ & $\begin{array}{c}8 \\
9 \\
11.1\end{array}$ & $\begin{array}{c}7 \\
8.6 \\
18.1\end{array}$ & $\begin{array}{r}6 \\
7.6 \\
21.0\end{array}$ & $\begin{array}{l}5 \\
5.6 \\
10.7\end{array}$ & $\begin{array}{c}8 \\
9 \\
11.1\end{array}$ & $\begin{array}{l}8 \\
8.8 \\
9.1\end{array}$ & $\begin{array}{c}7 \\
8.6 \\
18.6\end{array}$ & $\begin{array}{c}5 \\
6.8 \\
26.5\end{array}$ & $\begin{array}{l}6 \\
7.2 \\
16.7\end{array}$ & $\begin{array}{c}8 \\
9 \\
11.1\end{array}$ \\
\hline $\begin{array}{l}\text { Height of J wave } \\
\text { Corrected height } \\
\text { Per cent departure from } \\
\text { corrected figure }\end{array}$ & $\begin{array}{l}14 \\
14.8 \\
5.7\end{array}$ & $\begin{array}{l}12 \\
14 \\
14.3\end{array}$ & $\begin{array}{l}11 \\
13.2 \\
17\end{array}$ & $\begin{array}{l}13 \\
16 \\
18.7\end{array}$ & $\begin{array}{l}15 \\
16 \\
6.2\end{array}$ & $\begin{array}{l}15 \\
16 \\
6.2\end{array}$ & $\begin{array}{l}12 \\
14 \\
14.3\end{array}$ & $\begin{array}{l}11 \\
13.2 \\
16.7\end{array}$ & $\begin{array}{l}13 \\
14.2 \\
8.4\end{array}$ & $\begin{array}{r}17 \\
18.4 \\
7.6\end{array}$ \\
\hline
\end{tabular}

end, a sharp leftward deflection corresponds fairly well with the I-J complex. This is preceded by a rightward deflection which occurs late in time with respect to the $\mathrm{H}-\mathrm{I}$ complex, a finding which suggests that the forces which initiate the $H$ wave have no component in this direction. Although well marked in the record illustrated, this deflection is not nearly so constant as that corresponding to the I-J complex. It varies not only with respira-

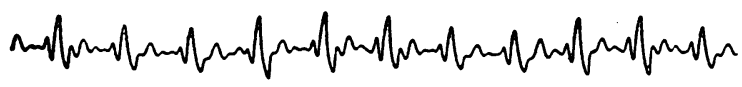

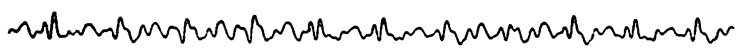
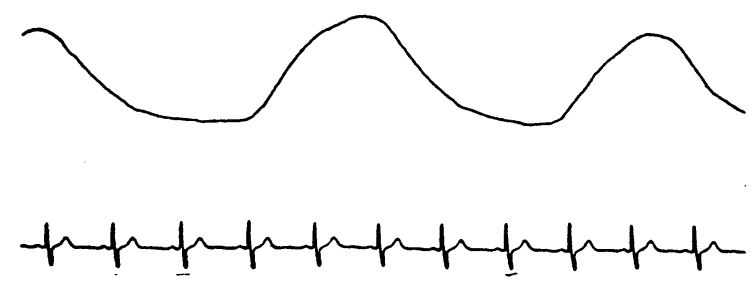

Fig. 6. A Typical Ballistocardiogram of a Young Healthy Adult Taken from the Two-Dimensional INSTRUMENT

The top curve illustrates the usual head to foot tracing, the second curve the side to side component taken from the head end of the table, the third curve is the transverse component taken from the center of the table and curve four is the transverse curve recorded from the foot end of the table. Curve 5 is a pneumograph, and the bottom curve is the electrocardiogram, Lead I. tion as to size, but may even reverse its direction, and in some slender patients drops out entirely.

Table II illustrates data taken from the record of a healthy young physician with a semi vertical heart. Two respiratory cycles are represented. Inspection of this data makes it quite apparent that the vectors represented by both the $\mathrm{I}$ and $\mathrm{J}$ wave decrease not only in magnitude during inspiration but also develop an increased departure in direction from the midline plane. Hence the error is not a constant one but tends to increase during expiration.

\section{CONCLUSIONS}

It should be apparent that we have so far considered the theory, design, construction and characteristics of the ballistic table alone. The actual condition which exists when the record is inscribed is not nearly so simple. In the final analysis, we are dealing not with a single vibrating system but with three: the heart, the body, and the table, which are successively coupled one to the other in complex fashion. Nickerson was aware of this in the design of his table. He ignored the coupling between the heart and the body, but after making various assumptions calculated that a critically damped table with a $f_{n}$ of 1.5 would move in unison with the body, and thus give a true picture at least of the motion imparted to the body by the heart beat. It has been shown experimentally that this is not correct (10).

From a theoretical analysis we have shown that a high frequency table must be used if the motion of the table is to reproduce the forces acting on it. The Fourier analysis demonstrates that a table with a natural frequency of at least 15 cycles per second must be used with a higher value of from 25 to 30 cycles desired. The damping should be viscous (proportional to the velocity) and should be sufficient to insure the table is between 50 and 
$100 \%$ critically damped with the subject on the table.

Thus the best that we could expect and do at this time was construct a rugged, sensitive and practical instrument which would reproduce with reasonable fidelity the motion of the body under specified conditions and with a natural frequency which would comfortably avoid resonance. This we have done with a table mounted on rods so that motion could be studied not only from head to foot but from side to side as well. The lateral component is now under study, but its value has not been demonstrated.

\section{SUM MARY}

1. The design and construction of a ballistocardiograph with two degrees of freedom corresponding to the frontal plane of the body has been described.

2. A theoretical analysis of the ballistocardiograph as a vibrating system, together with a harmonic analysis of three ballistic curves obtained on a healthy young adult has been offered in support of the design chosen.

3. A record taken with this instrument has been illustrated and the nature of the side component briefly discussed.

\section{BIBLIOGRAPHY}

1. Nickerson, J. L., and Curtis, H. J., The design of the ballistocardiograph. Am. J. Physiol., 1944, 142, 1.
2. Starr, I., Rawson, A. J., Schroeder, H. A., and Joseph, N. R., Studies on the estimation of cardiac output in man, and of abnormalities in cardiac function, from the heart's recoil and the blood's impact; the ballistocardiogram. Am. J. Physiol., 1939, 127, 1.

3. Brown, D. E. S., The design of the ballistocardiograph. J. Clin. Invest., 1942, 21, 294.

4. Starr, I., and Rawson, A. J., The vertical ballistocardiograph; changes in the cardiac output on assuming the erect posture, with a further theoretical study of the blood's impacts. Am. J. Physiol., 1941, 133, p. 461.

5. Starr, I., and Rawson, A. J., The vertical ballistocardiograph; experiments on the changes in the circulation on arising; with a further study of ballistic theory. Am. J. Physiol., 1941, 134, 403.

6. Krahl, V. E., A simple laboratory apparatus for the demonstration of cardiac ballistics. Science, 1947, 105, 393.

7. Wilkins, R. W., A tilting ballistocardiograph. Am. Heart J., 1943, 26, 351.

8. Gordon, J. W., On certain molar movements of the human body produced by the circulation of the blood. J. Anat. \& Physiol., 1877, 11, 533.

9. Henderson, Y., The mass-movements of the circulation as shown by a recoil curve. Am. J. Physiol., 1905, 14, 287.

10. Hamilton, W. F., Dow, P., and Remington, J. W., The relationship between the cardiac ejection curve and the ballistocardiographic forces. Am. J. Physiol., 1945, 144, 557.

11. Medical Physics, edited by Otto Glasser. Yearbook Publishers, Chicago, Ill., 1944, pp. 577-578.

12. DenHartog, J. P., Mechanical Vibrations. McGrawHill, New York City, 1947, 3rd Ed., pp. 63-67. 